\title{
Solitary Hypothalamus Triple Negative Metastasis from Luminal: A Primary Breast Carcinoma
}

Nuria Rodríguez-Salas ${ }^{1 *}$, Elia del Cerro ${ }^{2}$, Teresa Rivera ${ }^{3}$ and Agustín Acevedo ${ }^{4}$

${ }^{1}$ Medical Oncology Department, La Paz Hospital, Autónoma University, Madrid, Spain

${ }^{2}$ Radiotherapy Unit Quirón Hospital, Madrid, Spain

${ }^{3}$ Pathology Department, Hospital Infanta Leonor, Madrid, Spain

${ }^{4}$ Patology Department, Quirón Hospital, Madrid, Spain

\section{Case Presentation}

A 49 years old woman was diagnosed of bilateral and multicentric infiltrating ductal breast carcinoma with a luminal A phenotype (Figure 1) and blastic bone metastatic spread. She had a very good response to hormonotherapy and monthly zoledronic acid without visceral spread or bone events for three years. Then she consulted because of progressively asthenia, anorexia, nausea, dizziness, orthostatic, occasional abdominal pain, increased thirst and frequent urination and altered sleep-wake cycles. On physical examination, she appeared pallid without any other remarkable finding.

The white-cell count was $3270 / \mathrm{mm}^{3}$ with $55 \%$ neutrophils, $30 \%$ lymphocytes, Hemoglobin was $11.2 \mathrm{gr} / \mathrm{dL}$ with $35 \%$ of hematocrit, and her platelet count was $224,000 / \mathrm{mm}^{3}$. The serum sodium level was $146 \mathrm{mEq} / \mathrm{L}$, potassium $3.9 \mathrm{mEq} / \mathrm{L}$, creatinine $0.8 \mathrm{mg} / \mathrm{dL}$, blood urea nitrogen $12 \mathrm{mg} / \mathrm{dL}$ and glucose $77 \mathrm{mg} / \mathrm{dL}$ liver function was normal.

Considering that patient was under treatment with LHRH analogue (Goserline) plus peripheral antiestrogen (Anastrozol), analysis of endocrinological parameter were made, and showed the following findings: $3.55 \mathrm{FSH} \mathrm{mIU} / \mathrm{mL}, \mathrm{LH}<0.10 \mathrm{mIU} / \mathrm{mL}$, prolactin $82 \mathrm{ng} / \mathrm{mL}$, $3.83 \mathrm{TSH} \mathrm{mIU} / \mathrm{mL}$, free T4 $0.45 \mathrm{ng} / \mathrm{dL}$, T3 $1.41 \mathrm{ng} / \mathrm{mL}$, ACTH $8 \mathrm{pg} / \mathrm{mL}$ and basal cortisol $<1 \mathrm{ug} / \mathrm{dl}$.

She was urgently referred to an endocrinologist with the suspicious diagnosis of diabetes insipidus, central hypothyroidism (since the level of thyrotropin was normal) and severe secondary cortical adrenal insufficiency (low serum cortisol and normal level of ACTH). Endocrinologist indicated a magnetic resonance imaging (MRI) of the brain that showed a gadolinium-enhancing mass measuring $1.2 \mathrm{~cm}$ of the pituitary-hypothalamic axis, without other pathologic findings at other brain levels.

The systemic study was completed with a chest-abdominal and pelvis CT scan that showed stable multiple blastic bone metastasis without any other signs of disease progression, either in bone or visceral. The differential diagnosis of the intracranial mass was as follows: breast metastasis, other neoplastic disorder such as lymphoma or a primary tumour of the pituitary or hypothalamus. Less likely possibilities would be sarcoidosis, tuberculosis, autoimmune destruction and others.

\section{Treatment}

The patient initiated treatment with dexamethasone, desmopressin acetate with a very good and quick clinical and biochemical response.

The patient was later referred to the neurosurgeon, with the aim to provide relief of symptoms resulting from mass effect of the tumour, and also to establish a histologic diagnosis of the mass, to improve local control, and perhaps to provide a potential benefit of survival. She underwent a frontal craniotomy and partial excision of the hypothalamus mass was made without any surgical complications.

The histopathological exam of the surgical biopsy specimen revealed a triple negative ductal carcinoma because of the negative

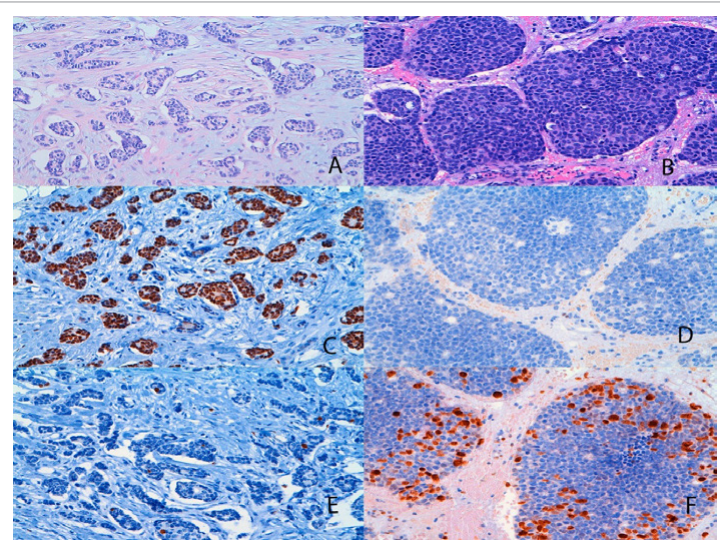

Figure 1: A: Breast primary ductal adenocarcinoma grade $2(H / E)$. B: Brain Metastasis $(\mathrm{H} / \mathrm{E})$. C: Positive Estrogen receptor in primary tumour. D: Negative estrogen receptor in metastasis. E: Low Ki67 immunostaining in primary tumour. F: High Ki67 immunostaining in metastasis.

results for the exam of oestrogen and progesterone receptors and negative immunostaining of human epidermal growth receptor type 2 (HER2) (Figure 1).

Four weeks later stereotactic radiation therapy was initiated for the residual lesion (Figure 2).

\section{Outcome and Follow-Up}

On a follow up visit the brain MR control, eight weeks under complete de radiosurgery show partial response of the hyphotalamic mass, complete response of the symptoms, and continue with the previous systemic therapy, without any other intracranial lesion or evidence of systemic progression with a follow up of two years.

\section{Discussion}

With a low frequency hypopituitarism is caused by malignant primary or metastatic tumours. Metastasis in this location is also an unusual manifestation of systemic cancer, with a reported incidence of $1 \%$ to $3.6 \%[1]$.

*Corresponding author: Nuria Rodríguez-Salas, Medical Oncology Department, La Paz Hospital, Autónoma University, Madrid, Spain, Tel: +34914975100; E-mail: nuria.rodriguez@salud.madrid.org

Received October 13, 2016; Accepted December 26, 2016; Published December 28, 2016

Citation: Rodríguez-Sala N, Cerro ED, Rivera T, Acevedo A (2016) Solitary Hypothalamus Triple Negative Metastasis from Luminal: A Primary Breast Carcinoma. J Mol Biomark Diagn S2: 025. doi:10.4172/2155-9929.S2-025

Copyright: @ 2016 Rodríguez-Salas N, et al. This is an open-access article distributed under the terms of the Creative Commons Attribution License, which permits unrestricted use, distribution, and reproduction in any medium, provided the original author and source are credited 


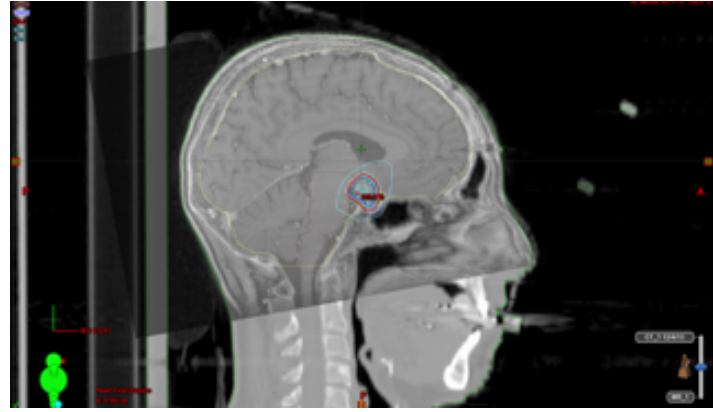

Figure 2: Four weeks later stereotactic radiation therapy was initiated for the residual lesión.

Breast and lung cancer are the most common tumours that metastasize to the pituitary gland. The posterior pituitary may be more prone to metastases because of its direct systemic supply of arterial blood, whereas the adenohypophysis receives blood from the hypophyseal portal system. Some researchers have reported a greater predilection for the involvement of the anterior pituitary in breast cancer, and they are often asymptomatic [2]. Nevertheless, in symptomatic cases diabetes insipidus is the most frequent finding [3]. Other symptoms could be headache, visual-field defects and those related with anterior pituitary dysfunction. In this cases it is prioritary to look for corticotropin deficiency which can lead to adrenal crisis and death, if it is no earlier recognized $[4,5]$.

Breast cancer is a complex and heterogeneus neoplasm. Gene expression profiling studies have identified at least four major breast cancer subtypes: luminal A, luminal B, HER2, and basal-like. These subtypes differ in regard to their patterns of gene expression, clinical features, response to treatment, and outcome [6,7]. Luminal A cancers tend to respond to endocrine therapy such as in our patient. Response to the luminal cancers to chemotherapy is variable, it is usually indicated in cases of visceral spread or in hormone-refractary cases. The basallike breast cancers show high expression of basal epithelial genes and basal cytokeratins, low expression of ER and ER-associated genes as well as low expression of HER 2 . They approximately constitute $15 \%$ of all breast cancers. Basal-like cancers have a poor prognosis and are not amenable to treatment with either endocrine therapy or trastuzumab because they are hormone receptor-negative and do not show HER2 overexpression or amplification. It has recently been reported the implication of BRCA-1 loss of function in this subtype of breast cancer [8]. Our patient was tested for BRCA 1 and BRCA-2 genes and they didn't show any significant mutation pattern.

Although the classification of breast cancers using gene expression profiling is of interest, three immunohistochemical markers (i.e. ER, PR and HER2) can be used as surrogates to approximate these various molecular subtypes for practical purposes [9]. In general, luminal cancers are ER- or PR-positive and HER2-negative, HER2 cancers are ER- or PR-negative andHER2 positive, and basal-like cancers are ER- or PR-negative and HER2-negative (so called triple negative). It should be noted, however, that although most basal-like cancers are triple negative, not all triple negative cancers are basal-like. The use of additional immunostains (particularly cytokeratin 5/6 and epidermal growth factor receptor) can be used to further refine the categorization of basal-like cancers $[10,11]$. In the patient, we report we used immunohistochemical markers in the primary and the metastatic biopsies.

Nowadays the study of the metastatic lesions when the breast cancer relapse is so useful. It has long been recognized that the hormone receptor status of metastases does not always correlate with that of the primary tumour, with approximately $20 \%$ to $30 \%$ conversion rate from ER-positive to ER-negative and much less frequently from ERnegative to ER-positive at relapse [12-15]. Indeed, the receptor status of the metastasis may be more predictive of response to therapy. One small study showed that, although $74 \%$ of patients with ER-positive primary tumours whose recurrent tumours retained ER expression responded to endocrine therapy, only $12 \%$ of patients with ER-positive primaries and ER-negative metastases likewise responded [8]. Similar discordances between hormone receptor content of primary breast cancer versus metastasis have also been recently documented in several other studies $[16,17]$ and loss of ER was associated with a significantly shorter median survival.

Furthermore, the metastatic tumor ER status was shown to be a better predictor of survival than the primary tumor ER status. In biopsies from patients who developed resistance to tamoxifen, changes in hormone receptor status, as well as in other signalling pathway molecules, such as HER2, have also recently been documented [18] Similarly, to ER, and perhaps even at a higher rate, a significant proportion of PR-positive tumours also lose PR expression in their metastasis [19], and loss of PR in sequential biopsies, particularly with intervening endocrine therapy, is associated with poorer survival as compared with patients retaining PR [20]. Nevertheless, trials in metastatic disease suggest that these tumours still benefit from endocrine therapy [21], although some data suggest that they may have a somewhat worse clinical outcome than ER-positive tumors [22].

In a pooled analysis of two prospective studies that included 289 patients, the rates of discordance in ER, PR, and HER2 between the primary and recurrent disease were $13 \%, 31 \%$, and $5.5 \%$, respectively. The results of the biopsy altered management in almost $14 \%$ of the patients [23]. In a separate prospective observational study that included 178 women, the conversion rate between primary and metastatic was similar to the findings above, with a discordance rate of 13, 28, and 3 percent for ER, PR, and HER2, respectively. Among those patients who demonstrated a conversion in receptor status, ER $(n=22)$ and PR ( $\mathrm{n}=47)$ status converted from positive to negative ( $78 \%$ and $72 \%$, respectively), and for HER2 status $(n=5)$, all went from positive to negative [24].

Different explanations have been suggested for this clinical and pathological discordance in the evolution of the breast cancer disease, including (a) intratumor heterogeneity of breast cancer, which can lead to clonal selection of different clones with distinct hormone receptor properties that can change over time; (b) changes within single cells themselves as an adaptive mechanism for treatment; (c) tumour dedifferentiation with the development of metastasis; or (d) technical laboratory difficulties in hormone receptor assessment of small biopsy specimens [25]. Regardless of the cause, the high level of this discordance between both ER and PR for primary and metastatic disease emphasizes the necessity for the integration, at progression, of a sequential biopsy and biomarker analysis (improved decision-making in the management of advanced breast cancer).

Clinical management of central nervous system metastatic spread of breast cancer in nowadays in change and needs a multidisciplinary team [26-27]. Three prospective, randomized trials have been conducted to evaluate the role of neurosurgery in patients with brain metastases. The first trial, reported by Patchell et al. [28], randomly assigned 48 patients with a single brain metastasis ( $6 \%$ with a breast primary) to either surgery followed by whole-brain radiotherapy (WBRT) versus 
WBRT alone. Patients in the combined-modality arm achieved better local control ( $20 \%$ vs $52 \%$; p: 0.02 ), improved median duration of functional independence ( 38 vs 8 weeks; p: 0.005), and longer overall survival ( 40 vs 15 weeks; p: 0.01 ), compared to the patients who received WBRT alone. These findings were replicated in a study of 63 patients (19\% with breast primaries) led by Noordijk et al. [29], in which patients treated with surgery and WBRT achieved prolonged survival (median 10 vs 6 months; p: 0.04) and functionally independent survival ( 7.5 vs 3.5 months; p: 0.06 ) compared to patients treated with WBRT alone. Of note, only patients with stable or absent extracranial disease appeared to derive a survival benefit from surgery; patients with progressive extracranial disease experienced a median survival of only 5 months irrespective of the allocated treatment. A third study reported no difference in either survival or functionally independent survival with the addition of surgery to WBRT [30]. In contrast to the first two trials, nearly half of the patients in this study were enrolled with coexisting extracranial metastases, and approximately $40 \%$ of patients had a Karnofsky performance status of $70 \%$ or less at study entry. In addition, the presence of a single brain lesion was categorized based on CT rather than MRI (which could have missed multiple lesions), and 10 out of 43 patients randomly assigned to radiotherapy underwent surgical resection at some point in their disease course, which may have further confounded the results.

In addition to the randomized trial data, the positive impact of surgical resection on survival has also been observed in large, retrospective studies and retains its significance even after adjusting for other prognostic factors [31]. Although there have been no trials of surgical resection limited to breast cancer patients, the totality of the data strongly indicates that surgical resection should be considered in patients with a single metastasis and stable extracranial disease [32].

Radiosurgery with the novel radiotherapy techniques is a very good alternative to those patients with unique or few lesions that couldn't be totally resected. In our patient, neurosurgery resection was incomplete due to the severe sequellae of a complete intent of remove of the hypothalamus lesion. The residual lesion was effectively treated with stereotactic radiosurgery [33].

\section{Learning Points}

In summary, we present a case of low risk metastatic breast cancer patient with a very good response to endocrine therapy for three years, but with an unusual clinical evolution, with a unique metastasis in the pituitary-hypothalamic axis and a critical clinical presentation. The biopsy of the CNS metastasis was mandatory in order to establish a correct diagnosis and to redefine the biological behaviour of the breast cancer and also base a more customized prognosis and therapy approximation. Multidisciplinary management of the patients is mandatory.

\section{References}

1. Fassett DR, Couldwell WT (2004) Metastases to the pituitary gland. Neurosurg Focus 16: E8.

2. Marin F, Kovacs KT, Scheithauer BW, Young WF Jr (1992) The pituitary gland in patients with breast carcinoma: A histologic and immunocytochemical study of 125 cases. Mayo Clin Proc 67: 949-956.

3. Kurkjian C, Armor JF, Kamble R, Ozer H, Kharfan-Dabaja MA (2005) Symptomatic metastases to the pituitary infundibulum resulting from primary breast cancer. Int J Clin Oncol 10: 191-194.

4. Chamarti B, Morris CA, Kaiser UB, Katz JT, Loscalzo J (2010) Stalking the diagnosis. N Eng J Med 362: 834-839.

5. Peppa M, Papaxoinis G, Xiros N, Raptis SA, Economopoulos T, et al. (2009)
Panhipopituitarism due to metastases to the hypothalamus and the pituitary resulting from primary breast cancer: A case report and review of the literature. Clin Breast Cancer 9: E4-E7.

6. Sorlie T, Perou CM, Tibshirani R, Aas T, Geisler S (2001) Gene expression patterns of breast carcinomas distinguish tumor subclasses with clinical implications. Proc Natl AcadSci USA 98: 10869-10874.

7. Brenton JD, Carey LA, Ahmed AA, Caldas C (2005) Molecular classification and molecular forecasting of breast cancer: Ready for clinical application? J Clin Oncol 23: 7350-7360.

8. Bai F, Smith MD, Chan HL, Pei XH (2013) Germline mutation of BRCA-1 alters the fate of mammary luminal cell and causes luminal-to-basal mmary tumor transformation. Oncogene 32: 2715-2745.

9. Hammond ME, Hayes DF, Dowsett M, Allred CD, Hagerty KL, et al. (2010) American society of clinical oncology/college of American pathologists guideline recommendations for immunohistochemical testing of estrogen and progesterone receptors in breast cancer. J Clin Oncol 28: 2784.

10. Nielsen TO, Hsu FD, Jensen K, Cheang M, Karaca G, et al. (2004) Immunohistochemical and clinical characterization of the basal-like subtype of invasive breast carcinoma. Clin Cancer Res 10: 5367-5374

11. Sotiriou C, Wirapati P, Loi S, Harris A, Fox S, et al. (2006) Gene expression profiling in breast cancer: Understanding the molecular basis of histologic grade to improve prognosis. J Natl Cancer Inst 98: 262-272.

12. Robertson JF (1996) Oestrogen receptor: A stable phenotype in breast cancer Br J Cancer $73: 5-12$

13. Hull DF, Clark GM, Osborne CK, Chamness GC, Knight WA, et al. (1983) Multiple estrogen receptor assays in human breast cancer. Cancer Res 43 413-416.

14. Spataro V, Price K, Goldhirsch A, Cavalli F, Simoncini E, et al. (1992) Sequentia estrogen receptor determinations from primary breast cancer and at relapse: Prognostic and therapeutic relevance. The International Breast Cancer Study Group (formerly Ludwig Group). Ann Oncol 3: 733-740.

15. Kuukasjarvi T, Kononen J, Helin H, Holli K, Isola J (1996) Loss of estrogen receptor in recurrent breast cancer is associated with poor response to endocrine therapy. J Clin Oncol 14: 2584-2589.

16. Broglio K, Moulder SL, Hsu L, Kau S, Pusztai, et al. (2008) Prognostic impact of discordance/concordance of triple-receptor expression between primary tumor and metastasis in patients with metastatic breast cancer. J Clin Oncol 26.

17. MacFarlane R, Speers C, Masoudi H, Chia S (2008) Molecular changes in the primary breast cancer versus the relapsed/metastatic lesion from a large population-based database and tissue microarray. J Clin Oncol 26.

18. Gutierrez MC, Detre S, Johnston S, Mohsin SK, Shou J, et al. (2005) Molecula changes in tamoxifen-resistant breast cancer: Relationship between estrogen receptor, HER-2, and p38 mitogen-activated protein kinase. J Clin Oncol 23 2469-2476.

19. Brankovic-Magic M, Jankovic R, Neskovic-Konstantinovic Z, NikolićVukosavljević D (2002) Progesterone receptor status of breast cancer metastases. J Cancer Res Clin Oncol 128: 55-60.

20. Gross GE, Clark GM, Chamness GC, McGuire WL (1984) Multiple progesterone receptor assays in human breast cancer. Cancer Res 44: 836-840.

21. Osborne CK, Yochmowitz MG, Knight WA, McGuire WL (1980) The value of estrogen and progesterone receptors in the treatment of breast cancer. Cancer 46: $2884-2888$

22. Keshgegian AA, Cnaan A (1996) Estrogen receptor-negative, progesterone receptor-positive breast carcinoma: poor clinical outcome. Arch Pathol Lab Med 120: 970-973.

23. Amir E, Clemons M, Purdie CA, Miller N, Quinlan P, et al. (2012) Tissue confirmation of disease recurrence in breast cancer patients: pooled analysis of multi-centre, multi-disciplinary prospective studies. Cancer Treat Rev 38 : 708-714.

24. de Dueñas EM, Hernández AL, Zotano AG, Carrión RM, López-Muñiz Jl, et al. (2014) Prospective evaluation of the conversion rate in the receptor status between primary breast cancer and metastasis: Results from the GEICAM 2009-03 Convert HER study. Breast Cancer Res Treat 143: 507-515.

25. Aparicio S, Caldas C (2013) The implications of clonal genome evolution for cancer medicine. N Eng J Med 368: 842-851. 
Citation: Rodríguez-Sala N, Cerro ED, Rivera T, Acevedo A (2016) Solitary Hypothalamus Triple Negative Metastasis from Luminal: A Primary Breast Carcinoma. J Mol Biomark Diagn S2: 025. doi:10.4172/2155-9929.S2-025

26. Costa R, Carneiro BA, Wainwright DA, Santa-Maria CA, Kumthekar P, et al. (2013) Developmental therapeutics for patients with breast cancer and central nervous system metastasis: Current landscape and future perspectives. Ann Oncol.

27. McKee MJ, Keith K, Deal AM, Garrett AL, Wheless AA, et al. (2016) A multidisciplinary breast cancer brain metastases clinic: The University of North Carolina experience. Oncologist 21: 16-20

28. Patchell RA, Tibbs PA, Walsh JW, Dempsey RJ, Maruyama Y, et al. (1990) A randomized trial of surgery in the treatment of single metastases to the brain N Engl J Med 322: 494-500.

29. Noordijk EM, Vecht CJ, Haaxma-Reiche H, Padberg GW, Voormolen JH, et al. (1994)The choice of treatment of single brain metastasis should be based on extracranial tumor activity and age. Int J Radiat Oncol Biol Phys 29: 711-717.
30. Mintz AH, Kestle J, Rathbone MP, Gaspar L, Hugenholtz H, et al. (1996) A randomized trial to assess the efficacy of surgery in addition to radiotherapy in patients with a single cerebral metastasis. Cancer 78: 1470-1476.

31. Lagerwaard FJ, Levendag PC, Nowak PJ, Eijkenboom WMH, Hanssens PJ, et al. (1999) Identification of prognostic factors in patients with brain metastases: A review of 1,292 patients. Int J Radiat Oncol Biol Phys 43: 795-803.

32. Leone JP, Lee AV, Brufsky AM (2015) Prognostic factors and survival of patients with brain metastasis from breast cancer who underwent craniotomy Cancer Med 4: 989-994.

33. Lippitz B, Lindquist C, Paddick I, Peterson D, O’Neill K, et al. (2013) Stereotactic radiosurgery in the treatment of brain metastases: The current evidence. Cancer Treat Rev 40: 48-59.
This article was originally published in a special issue, Cancer Biomarkers handled by Editor(s). Dr. Sudhir Srivastava, Cancer Biomarkers Research Group, National Institute of Health, USA; Dr. Shou-Jiang Gao, The University of Texas Health Science Centre at San Antonio, USA; Dr. Kenneth Maiese, University of Medicine \& Dentistry of New Jersey, New Jersey Medical School, USA 